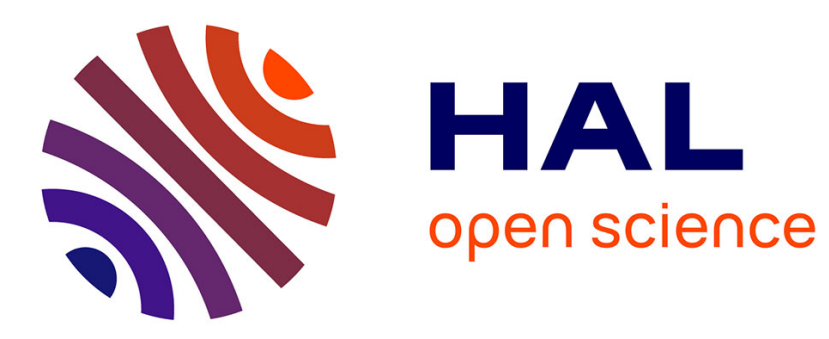

\title{
Hydro-mechanical modelling of landslides with a material instability criterion
}

Sylvain Lignon, Farid Laouafa, Florent Prunier, Huynh Dat Vu Khoa, Félix Darve

\section{- To cite this version:}

Sylvain Lignon, Farid Laouafa, Florent Prunier, Huynh Dat Vu Khoa, Félix Darve. Hydro-mechanical modelling of landslides with a material instability criterion. Geotechnique, 2009, 59 (6), pp.513-524. 10.1680/geot.7.00121 . ineris-00963152

HAL Id: ineris-00963152

https://hal-ineris.archives-ouvertes.fr/ineris-00963152

Submitted on 21 Feb 2022

HAL is a multi-disciplinary open access archive for the deposit and dissemination of scientific research documents, whether they are published or not. The documents may come from teaching and research institutions in France or abroad, or from public or private research centers.
L'archive ouverte pluridisciplinaire HAL, est destinée au dépôt et à la diffusion de documents scientifiques de niveau recherche, publiés ou non, émanant des établissements d'enseignement et de recherche français ou étrangers, des laboratoires publics ou privés. 


\title{
Hydro-mechanical modelling of landslides with a material instability criterion
}

\author{
S. LIGNON*, F. LAOUAFA $\uparrow$, F. PRUNIER*, H. D. V. KHOA $\ddagger$ and F. DARVE*
}

\begin{abstract}
The Petacciato landslide that occurred between 1906 and 1966 along a stretch of the Adriatic coast (Italy) and the Trevoux landslide that appeared in 1983 in France are analysed using Hill's material sufficient stability condition, which is based on the sign of the second-order work. Local and global sufficient stability criteria allow detecting and describing the instability phenomena, respectively, at the material point level and for the whole domain. By considering the non-associated Plasol elastoplastic constitutive model and the second-order work criterion, it is shown that unstable stress-strain states can be reached in plane strain conditions, strictly inside the plastic limit criterion. The two landslides that occurred in Petacciato and Trevoux are then analysed by modelling unsaturated hydro-mechanical coupling. The analysis is carried out using the Lagamine finite element code. This original approach to slope stability analysis makes it possible successfully to exhibit the landslide mechanism observed on these slopes after a long rainy period: this could not be described with the classical methods.
\end{abstract}

KEYWORDS: failure; landslides; numerical modelling
Le glissement de terrain de Petacciato, survenu de 1906 à 1966 le long de la côte Adriatique (Italie), et celui qui est survenu à Trévoux, en France, en 1983, sont analysés en utilisant la condition suffisante de stabilité matériel de Hill, basée sur le signe de travail du second ordre. Des critères locaux et globaux de stabilité suffisante permettent de détecter et de décrire le phénomène de l'instabilité respectivement au niveau du point matériel et pour l'intégralité du domaine. En examinant le modèle constitutif élastoplastique non associé, Plasol, ainsi que le critère basé sur le travail du second ordre, nous montrons qu'il est possible en déformations planes, d'atteindre des états de contrainte-déformation instables, situés, strictement à l'intérieur de la surface limite plastique. On procède ensuite à l'analyse des deux glissements de terrain survenus à Petacciato (Italie) et à Trévoux (France) à l'aide d'une modélisation couplée hydromécanique non saturé. On effectue l'analyse en utilisant le code aux éléments finis Lagamine. Cette méthode originale pour l'analyse de la stabilité des pentes permet de présenter avec succès le mécanisme de glissement de terrain relevé sur ces pentes après une longue période de précipitations: ce qui ne peut être décrit par les méthods classiques.

\section{INTRODUCTION}

Slope stability analysis is a classic problem in geotechnical engineering (Darve \& Vardoulakis 2004). The usual approaches are generally considered in the framework of plasticity theory and using strong assumptions. The description of these methods can be easily found in the literature (Duncan, 1996; Espinoza et al., 1996). Two common approaches are briefly reviewed.

(a) A first analytical method, based on the perfect associated plasticity assumption, relates the inception of failure directly to the friction angle of the material.

(b) The second method relies on limit equilibrium analysis using slice methods. Usually, an analysis is carried out by assuming the failure surface geometry (or critical slip surface) and the mechanical properties of the interface along this failure surface.

It is well known, however, that the soils exhibit a pathdependent and non-linear, non-associated behaviour. An accurate analysis of a slope stability problem and the related failure mechanism needs to consider how strains and the

\footnotetext{
Manuscript received 23 July 2007; revised manuscript accepted 31 October 2008. Published online ahead of print March 2009.

Discussion on this paper is welcomed by the editor.

* Laboratoire Sols, Solides, Structures-Risques, BP 53, 38041 Grenoble cedex 9, France

$\dagger$ INERIS, Unité Risques Naturels, Ouvrages \& Stockages/Direction des Risques du Sol et du Sous-Sol, BP 2, 60550 Verneuil en Halatte - France

† Norwegian Geotechnical Institute (NGI), P.O. Box 3930 Ullevaal Stadion, N-0806 Oslo, Norway
}

path dependency evolve by means of an accurate constitutive model. The use of continuum methods such as the finite element method (Duncan, 1996; Griffiths \& Lane, 1999; Zienkiewicz \& Taylor, 1994) have recently been developed for this purpose. These more accurate approaches, generally based on elasto-plasticity, usually analyse the landslide mechanism by considering a failure criterion based on the so-called plastic limit condition (Mohr-Coulomb's criterion) and the plastic strain localisation condition (Rice, 1976). Modelling slope stability problems with these modern theories has led to great improvements in the conventional theories.

A certain class of landslides can be well described and predicted using localisation theory. When the sliding process is driven by the inception of a narrow band, the finite element model of localised deformation into a shear band will be able to detect the bifurcation of the strain mode and accurate modelling of the mechanical problem can be expected. Although localisation theory is well established, the post-localisation and the behaviour in the shear band remain an open question (Vardoulakis, 1976). Several approaches such as non-local continuum, second-gradient theory are proposed, but none of these different methods can capture all the possible failure modes. These methods only allow an objective description of localised failure to be obtained. Indeed, material instabilities can lead to diffuse modes of failure and not only localised ones. The liquefaction phenomenon in the case of loose sands is a well-known example of this type of failure mode with no shear band formation (Darve, 1996; Darve \& Chau, 1987; Darve et al., 2000). In the slope stability problem, some landslides with low (less than $14^{\circ}$ ) to very low (less than $8^{\circ}$ ) slope angles, where the 
failure is often of the diffuse type, cannot be explained using either classical empirical methods or numerical limit analyses (plasticity theories). In this scenario, a soil mass moves downhill as a flow slide. New approaches are therefore necessary to account for these landslide mechanisms.

Hill's sufficient condition of stability (Hill, 1958), which is based on the sign of the second-order work, seems to be a pertinent stability criterion to detect these diffuse modes of failure, essentially because it is the first bifurcation criterion which is reached along any loading path (if flutter instabilities are excepted). Indeed Hill's criterion can be satisfied, along such a path, before Rice's criterion (vanishing values of the determinant of the acoustic tensor, corresponding to a particular case of the Hill's condition) and before MohrCoulomb's criterion (vanishing values of the determinant of the constitutive matrix) in the case of non-associated materials such as soils (Bigoni and Hueckel, 1991; Darve \& Laouafa, 1994; Nova, 1994, 2004).

In this paper, the Trevoux and Petacciato landslides are analysed using this second-order work criterion. The first part briefly presents the elasto-plastic model (Barnichon, 1998) used in the Lagamine finite element code. Then the definition of Hill's criterion is reviewed and the formulations of both local and global stability criteria used here in the context of the finite element method are given. The landslides are modelled as a coupled unsaturated hydro-mechanical problem, where the loading corresponds to a rising water table. In each case, the soil parameters are calibrated with experimental results. While the classical approaches, such as the $c-\varphi$ reduction method or the gravity load method, cannot explain landslides (Laouafa \& Darve, 2002) for low slope angles (especially the Petacciato landslide), it will be seen that the method based on the second-order work criterion is effective.

The topical research aims to establish the relation between the second-order work criterion and a spectral analysis of the global/symmetric stiffness matrix. This might allow the critical loading levels related to vanishing eigen values to be determined and the failure modes related to the associated eigen vectors to be described. The corresponding results will be published in a subsequent paper.

\section{THE TWO LANDSLIDES}

In this paper, two landslides are analysed using hydromechanical modelling: the Trevoux landslide in France and the Petacciato landslide in Italy. The coupled hydro-mechanical model is necessary to represent the effect of a high rainfall event on the slopes, which is simulated here by a rising water table. These sites are outlined in this section.

\section{The Trevoux site}

The landslide of interest occurred on the Trevoux hillside (France) (Fig. 1) after heavy rainfall in 1983. A typical cross-section of the Trevoux hillside is shown in Fig. 2 with a water level at $5.5 \mathrm{~m}$ (the usual level) and $10.0 \mathrm{~m}$ (during the high rainfall period) above the base of the Saône River.

The mesh of the hillside is depicted in Fig. 3. It is composed of 1403 quadratic triangular elements (six nodes, seven integration points) with 5640 degrees of freedom. The bottom boundary was assumed to be impervious. The other boundaries of the mesh were assumed to be permeable and free of traction, except the underwater portion where water pressures are developing over the course of the rainfall event.

The model is based on the plane strain hypothesis. The initial conditions correspond to the water level at the bottom of the model $\left(u_{z}=0\right)$ and the initial stress field stems from the gravity load. The suction is hydrostatically distributed: this
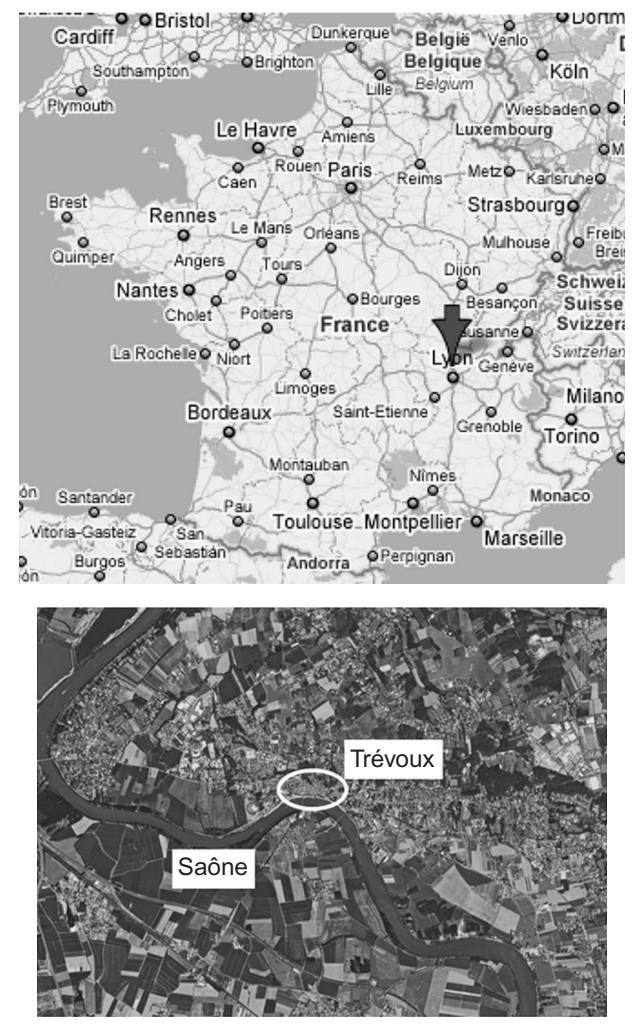

Fig. 1. Geographic location of the studied area. Copyright 2008 Google-map data. Copyright 2008-Tele Atlas

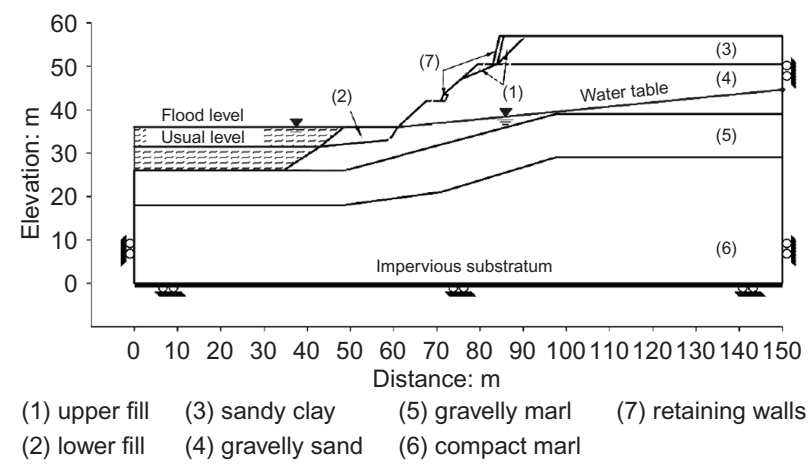

Fig. 2. Typical cross-section of the Trevoux landslide

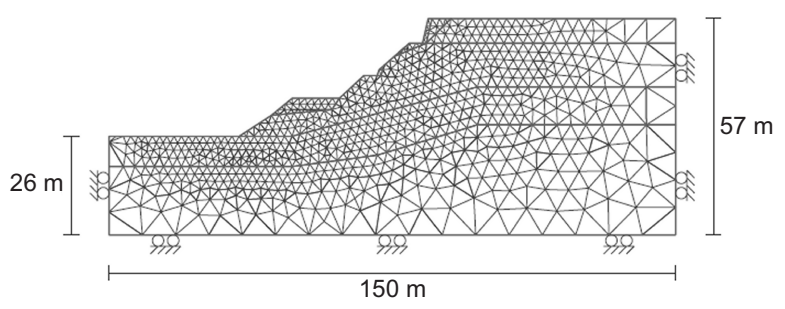

Fig. 3. Finite element mesh of the Trevoux landslide

allows the calculation of $p_{\mathrm{w}}$ and $\sigma_{\mathrm{ew}}$ using the hydro-mechanical equations and then the determination of $\sigma^{\prime}$ throughout the model. Moreover, the model allows large strains.

\section{The Petacciato site}

The area of Petacciato lies along a stretch of the Adriatic coast of Italy (Fig. 4) and has been the subject of detailed geological and geomorphological surveys and analyses, including the interpretation of the possible mechanisms causing instability phenomena (Studio Geotecnico Italiano, 2004). 

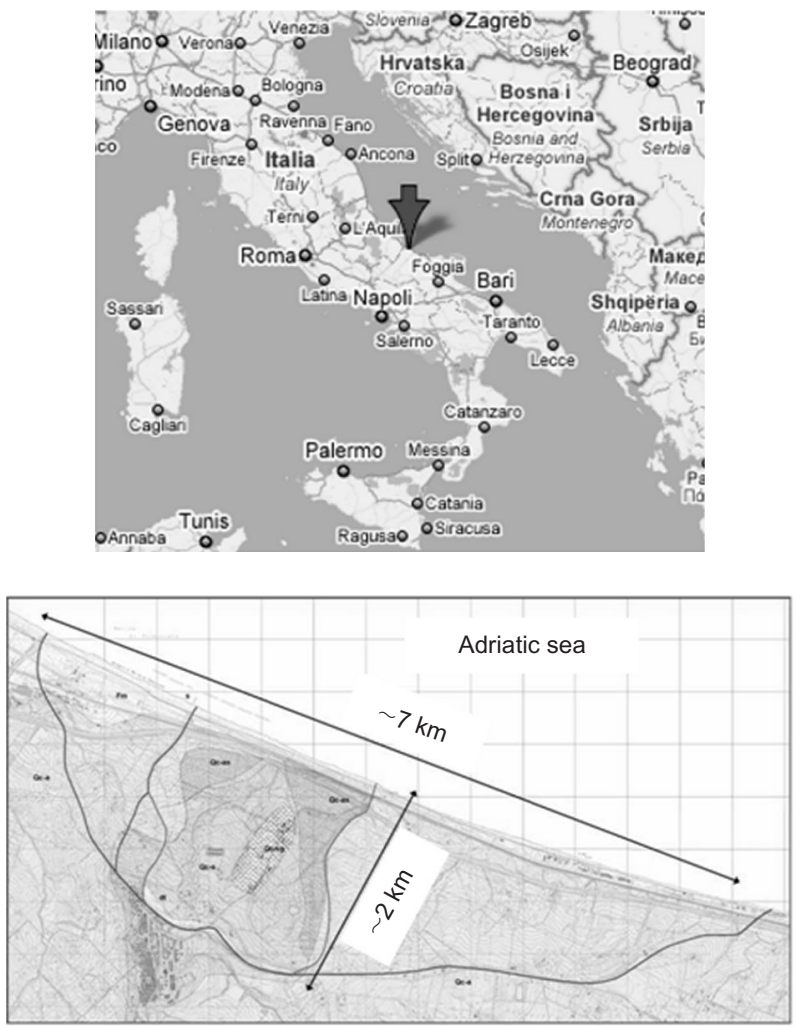

Fig. 4. Geographic location of the studied area. Copyright 2008 Google-map data. Copyright 2008-Tele Atlas

The Petacciato landslide covers an area approximately $2 \mathrm{~km}$ wide, $7 \mathrm{~km}$ long and over $200 \mathrm{~m}$ difference in height. Fig. 5 depicts the geometry of a typical section where the failure surface was found between 70 and $90 \mathrm{~m}$ in depth by way of borehole logging, clinometric measurements and piezometers.

The slope is assumed to be materially homogeneous. The finite element mesh used in this simulation is depicted in Fig. 6. It comprises 2600 quadratic triangular elements (six nodes, seven gauss points). The horizontal degrees of freedom of the two vertical boundaries of the domain and the vertical degrees of freedom of the bottom boundary are assumed to be blocked. The computations are done in plane strain conditions.

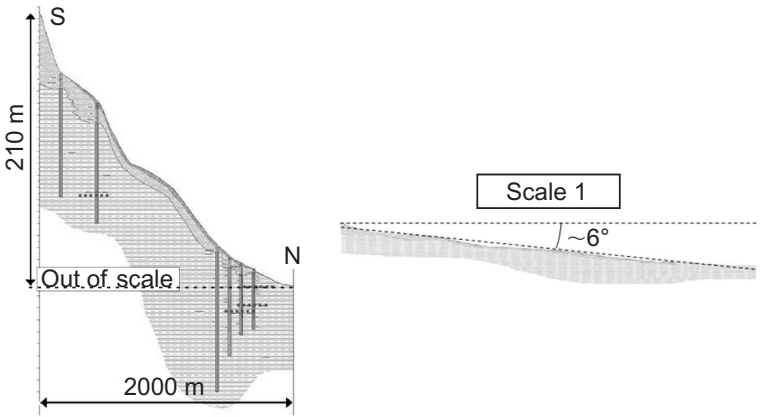

Fig. 5. Typical cross-section studied of the Petacciato landslide (vertical lines on left figure: localisation of borehole logging)

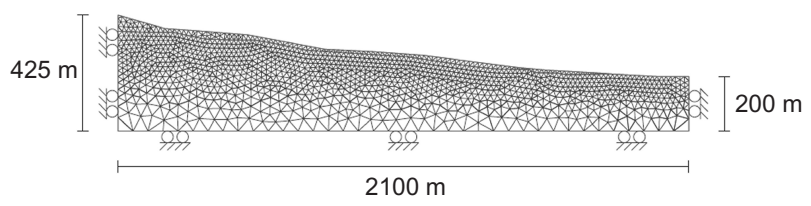

Fig. 6. Finite element mesh of the Petacciato coastal slope

\section{DESCRIPTION OF THE NON-LINEAR CONSTITUTIVE} MODEL

The two landslides presented above were modelled with the Lagamine finite element code developed by the University of Liège (Barnichon, 1998). The soil behaviour is based on the PLASOL non-associated elasto-plastic model.

This model is a frictional or pressure-sensitive elastoplastic constitutive model developed mainly for geomaterials. It reproduces soil hardening and can describe the nonassociated flow rule. Moreover, it is based on the Van Eekelen (Van Eekelen, 1980) yield criterion.

This section provides a brief introduction to the main characteristics of this constitutive relation.

\section{Van Eekelen yield criterion}

Let us call $I_{\sigma}, I_{2 \sigma}$ and $I_{3 \sigma}$ the first, second and third stress tensor invariants, respectively. Lode angle $\beta$ is given by

$$
\cos 3 \beta=\frac{\sqrt{6} I_{3 \sigma}}{\sqrt{\left(I_{2 \sigma}\right)^{3}}}
$$

The expression of the Van Eekelen yield criterion (Van Eekelen, 1980) is then stated as follows

$$
f=I_{2 \sigma}+m\left(I_{\sigma}-\frac{3 c}{\tan \varphi_{\mathrm{c}}}\right)=0
$$

where $c$ is the cohesion, $\varphi_{c}$ is the friction angle under triaxial compression paths and $m$ is a coefficient defined as follows

$$
m=a(1+b \sin 3 \beta)^{n}
$$

Parameters $a$ and $b$ are functions of the friction angle $\varphi_{\mathrm{c}}$ (compression path) and $\varphi_{\mathrm{e}}$ (extension path)

$$
b=\frac{\left(r_{\mathrm{c}} / r_{\mathrm{e}}\right)^{1 / n}-1}{\left(r_{\mathrm{c}} / r_{\mathrm{e}}\right)^{1 / n}+1}, \quad a=\frac{r_{\mathrm{c}}}{(1+b)^{n}}
$$

where $r_{\mathrm{c}}$ and $r_{\mathrm{e}}$ are the reduced radii (in the deviatoric stress plane) in compression and in extension for triaxial tests, respectively

$$
r_{\mathrm{c}}=\frac{2 \sin \varphi_{\mathrm{c}}}{\sqrt{3}\left(3-\sin \varphi_{\mathrm{c}}\right)}, \quad r_{\mathrm{e}}=\frac{2 \sin \varphi_{\mathrm{e}}}{\sqrt{3}\left(3+\sin \varphi_{\mathrm{e}}\right)}
$$

Exponent $n$ controls the shape of the yield surface. Following Van Eekelen's conclusions, the default value $n=-0.229$ maintains the convexity of the yield surface.

The Mohr-Coulomb, Drücker Prager and Van Eekelen yield surfaces in the deviatoric plane are compared in Fig. 7 for a given value of $\varphi_{\mathrm{c}}$. The Van Eekelen yield surface will be used because it fits the experimental results better.

The non-linear constitutive model

In the PLASOL constitutive model, the plastic potential depends on hardening variables. This is introduced through a hyperbolic evolution of the internal variables (the friction angle and the cohesion) as a function of the Von Mises equivalent plastic strain $\varepsilon_{\mathrm{eq}}^{p}$

$$
\begin{aligned}
\varepsilon_{\mathrm{eq}}^{p} & =\int_{0}^{t} \dot{\varepsilon}_{\mathrm{eq}}^{p} \mathrm{~d} t=\int_{0}^{t} \sqrt{\frac{2}{3} \operatorname{tr}(\underline{\dot{e}})^{2}} \mathrm{~d} t \\
\text { with } \underline{\dot{e}} & =\underline{\dot{\varepsilon}}^{p}-\frac{\operatorname{tr}\left(\underline{\dot{\varepsilon}}^{p}\right)}{3} \underline{1}
\end{aligned}
$$




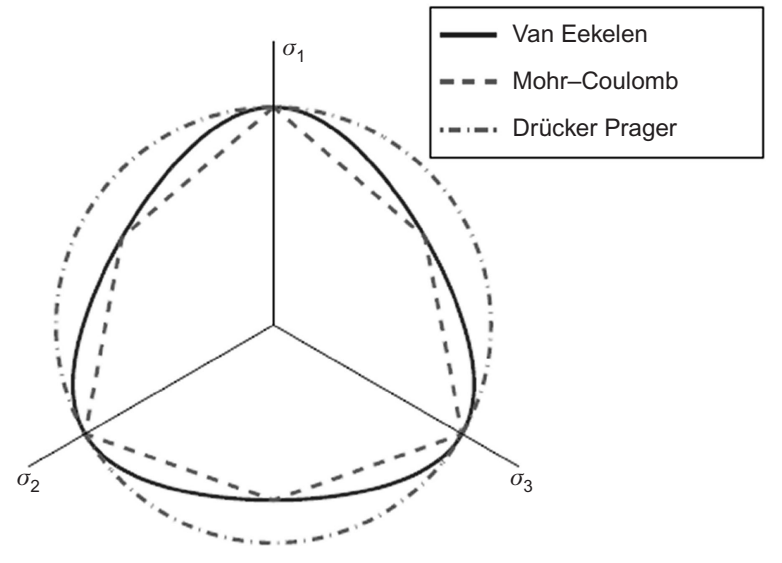

Fig. 7. Mohr-Coulomb, Drücker Prager and Van Eekelen limit surfaces in the deviatoric stress plane for $\varphi_{\mathrm{c}}=\varphi_{\mathrm{e}}=19^{\circ}$

$$
\begin{aligned}
& \varphi_{\mathrm{c}}=\varphi_{\mathrm{c} 0}+\frac{\left(\varphi_{\mathrm{cf}}-\varphi_{\mathrm{c} 0}\right) \varepsilon_{\mathrm{eq}}^{p}}{B_{\mathrm{p}}+\varepsilon_{\mathrm{eq}}^{p}} \\
& \varphi_{\mathrm{e}}=\varphi_{\mathrm{e} 0}+\frac{\left(\varphi_{\mathrm{ef}}-\varphi_{\mathrm{e} 0}\right) \varepsilon_{\mathrm{eq}}^{p}}{B_{\mathrm{p}}+\varepsilon_{\mathrm{eq}}^{p}} \\
& c=c_{0}+\frac{\left(c_{\mathrm{f}}-c_{0}\right) \varepsilon_{\mathrm{eq}}^{p}}{B_{\mathrm{c}}+\varepsilon_{\mathrm{eq}}^{p}}
\end{aligned}
$$

Parameters $B_{\mathrm{p}}$ and $B_{\mathrm{c}}$ represent, respectively, the values of the equivalent plastic strains for which half of the hardening on friction angles and cohesion is achieved (Fig. 8).

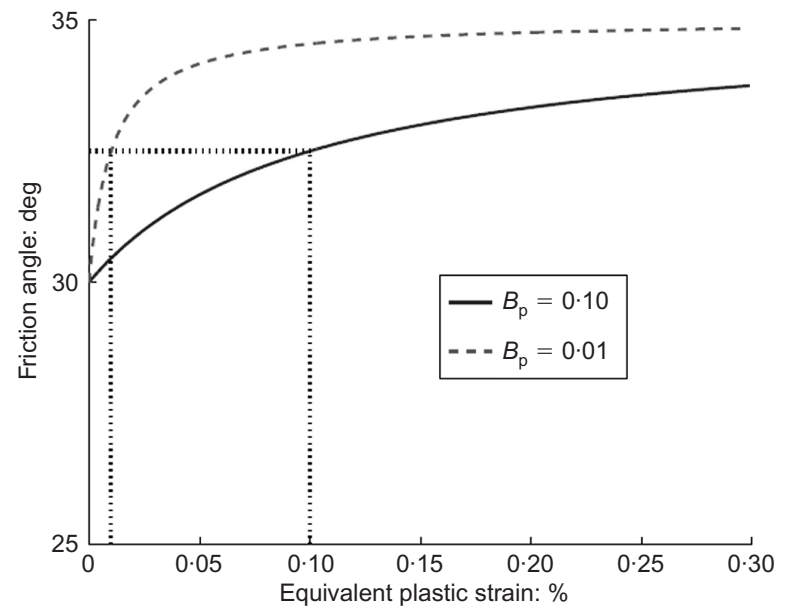

Fig. 8. Example of hardening hyperbolic laws for two values of $B_{\mathrm{p}}\left(\varphi_{0}=30^{\circ}, \varphi_{\mathrm{f}}=35^{\circ}\right)$
The advantage of the PLASOL model is its simplicity, but it cannot reproduce the softening of the soil, as will be seen in the calibration of the soil parameters. This model with the Van Eekelen yield criterion was implemented in the Lagamine finite element code by Barnichon (Barnichon, 1998) and will be used for the numerical simulation.

\section{Trevoux soil parameters}

The soil parameters of the Trevoux hillside were determined using the results of laboratory tests obtained by a company called SAGE (Gaden \& Desvarreux, 2001, 2002) and several investigations carried out by Bureau de Recherches Géolgoques et Minières (BRGM, 1983). Fig. 2 presents the spatial distribution of the Trevoux hillside soils, with the mechanical parameters given in Table 1 .

\section{Petacciato soil parameters}

The soil parameters given in Table 2 were determined by calibrating SGI's laboratory tests (SGI, 2004). Fig. 9 presents the comparison between the experimental results of drained triaxial tests and those obtained using the PLASOL model. Two observations can be made from this figure

(a) the Plasol model does not allow the description of the softening

(b) experimental data are quite unusual because this soil presents a significant peak in the $\left(q-\varepsilon_{1}\right)$ plane while negligible dilatancy in the $\left(\varepsilon_{\mathrm{v}}-\varepsilon_{1}\right)$ plane.

Owing to these two features, the model has been calibrated in order to fit the initial tangent and the maximum value.

Table 2. Mechanical parameters of the Petacciato soils

\begin{tabular}{|c|c|c|c|c|c|c|c|c|}
\hline Soil parameters & Symb. & Unit & $\begin{array}{l}\text { Upper fill } \\
\text { (1) }\end{array}$ & $\begin{array}{l}\text { Low fill } \\
\text { (2) }\end{array}$ & $\begin{array}{c}\text { Sand clay } \\
\text { (3) }\end{array}$ & $\begin{array}{c}\text { Gravelly sand } \\
\text { (4) }\end{array}$ & $\begin{array}{c}\text { Gravelly marl } \\
(5)\end{array}$ & $\begin{array}{c}\text { Compact marl } \\
\text { (6) }\end{array}$ \\
\hline $\begin{array}{l}\text { Grain specific weight } \\
\text { Young modulus } \\
\text { Poisson's ratio } \\
\text { Porosity } \\
\text { Intrinsic permeability } \\
\text { Initial friction angle } \\
\text { Final friction angle } \\
\text { Coefficient } B_{\mathrm{p}} \\
\text { Cohesion } \\
\text { Dilatancy angle }\end{array}$ & $\begin{array}{c}\rho_{\mathrm{s}} \\
E \\
v \\
n \\
k_{\mathrm{W}} \\
\varphi_{0} \\
\varphi_{\mathrm{f}} \\
B_{\mathrm{p}} \\
c \\
\psi_{0}=\psi_{\mathrm{f}}\end{array}$ & $\begin{array}{c}\mathrm{kN} / \mathrm{m}^{3} \\
\mathrm{MPa} \\
- \\
- \\
\mathrm{m}^{2} \\
\mathrm{deg} \\
\mathrm{deg} \\
\overline{\mathrm{kPa}} \\
\mathrm{deg}\end{array}$ & $\begin{array}{l}25 \cdot 71 \\
38 \cdot 6 \\
0 \cdot 29 \\
0 \cdot 3 \\
10^{-10} \\
10 \cdot 0 \\
35 \cdot 0 \\
0 \cdot 008 \\
10 \cdot 0 \\
0\end{array}$ & $\begin{array}{l}25 \cdot 71 \\
38 \cdot 6 \\
0 \cdot 29 \\
0 \cdot 3 \\
10^{-10} \\
10 \cdot 0 \\
35 \cdot 0 \\
0 \cdot 008 \\
15 \cdot 0 \\
0\end{array}$ & $\begin{array}{l}29 \cdot 00 \\
30 \cdot 0 \\
0 \cdot 29 \\
0 \cdot 5 \\
10^{-10} \\
10 \cdot 0 \\
35 \cdot 0 \\
0 \cdot 008 \\
1 \cdot 0 \\
3 \cdot 2\end{array}$ & $\begin{array}{l}28 \cdot 00 \\
20 \cdot 0 \\
0 \cdot 29 \\
0 \cdot 5 \\
10^{-10} \\
10 \cdot 0 \\
40 \cdot 0 \\
0 \cdot 008 \\
1 \cdot 0 \\
3 \cdot 2\end{array}$ & $\begin{array}{c}27 \cdot 14 \\
46 \cdot 3 \\
0 \cdot 29 \\
0 \cdot 3 \\
10^{-14} \\
35 \cdot 0 \\
35 \cdot 0 \\
0 \cdot 008 \\
100 \cdot 0 \\
2 \cdot 0\end{array}$ & $\begin{array}{c}28 \cdot 57 \\
100 \cdot 0 \\
0 \cdot 29 \\
0 \cdot 3 \\
10^{-14} \\
35 \cdot 0 \\
35 \cdot 0 \\
0 \cdot 008 \\
100 \cdot 0 \\
2 \cdot 0\end{array}$ \\
\hline
\end{tabular}

\begin{tabular}{l|c|c|c}
\hline Soil parameters & Symbols & Unit & Blue-grey clay \\
\hline Grain specific weight & $\rho_{\mathrm{s}}$ & $\mathrm{kN} / \mathrm{m}^{3}$ & $27 \cdot 40$ \\
Young modulus & $E$ & $\mathrm{MPa}$ & $95 \cdot 0$ \\
Poisson's ratio & $v$ & - & $0 \cdot 21$ \\
Porosity & $n$ & - & $0 \cdot 3$ \\
Intrinsic permeability & $k_{\mathrm{w}}$ & $\mathrm{m}^{2}$ & $10^{-17}$ \\
Initial friction angle & $\varphi_{0}$ & $\mathrm{deg}$ & $1 \cdot 0$ \\
Final friction angle & $\varphi_{\mathrm{f}}$ & $\mathrm{deg}$ & $19 \cdot 0$ \\
Coefficient $B_{\mathrm{p}}$ & $B_{\mathrm{p}}$ & - & $0 \cdot 01$ \\
Initial cohesion & $c_{0}$ & $\mathrm{kPa}$ & $10^{-3}$ \\
Final cohesion & $c_{\mathrm{f}}$ & $\mathrm{kPa}$ & 171 \\
Coefficient $B_{\mathrm{c}}$ & $B_{\mathrm{c}}$ & - & $0 \cdot 02$ \\
Dilatancy angle & $\psi_{0}=\psi_{\mathrm{f}}$ & $\mathrm{deg}$ & 0 \\
\hline
\end{tabular}

Table 1. Mechanical parameters of the Trevoux soils 

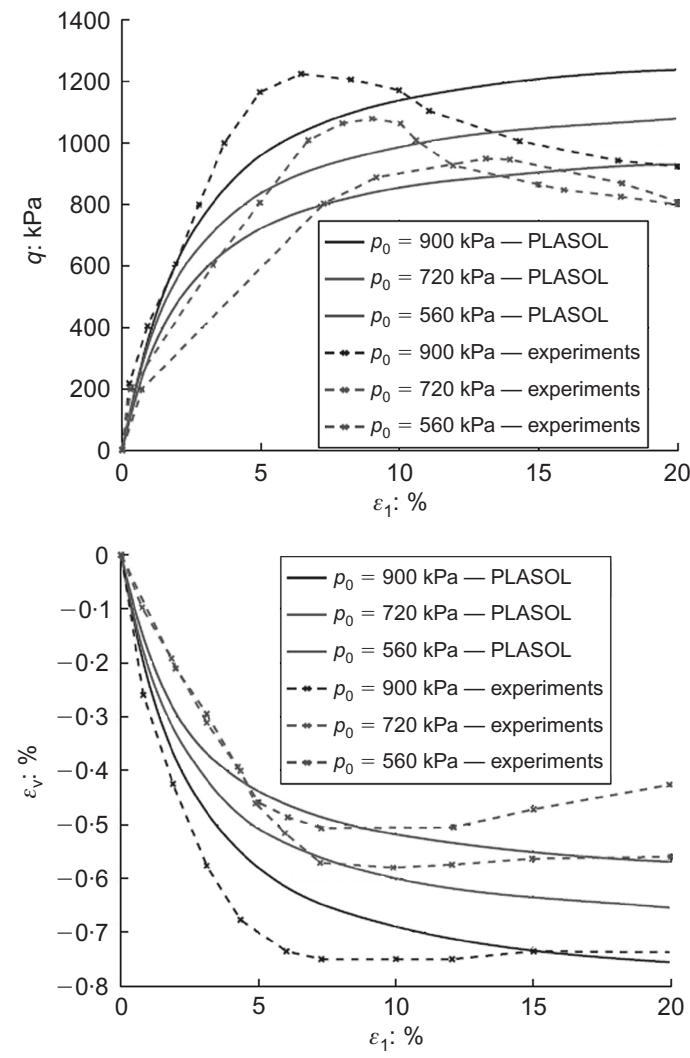

Fig. 9. Experimental data and numerical results of drained triaxial tests on Petacciato soil $\left(q\right.$ : deviatoric stress; $\varepsilon_{1}$ : axial strain; $\varepsilon_{v}$ : volumetric strain)

\section{HYDRO-MECHANICAL COUPLING FOR THE NON- SATURATED SOIL}

It is well known that in a non-saturated soil, the water flow is more complex than when it is saturated, essentially because the balance equations and the constitutive relation are strongly coupled.

The governing equations of the non-saturated soil problem are described by a time-dependent model of water transfer. It can be considered that at each time, the air pressure $p_{\mathrm{a}}$ is equal to the atmospheric pressure $p_{\mathrm{atm}}$. To simplify the analysis, $p_{\mathrm{a}}=p_{\mathrm{atm}}=0$ is chosen in the following discussion. This assumption is generally valid for sands, for which the air phase is connected to the free surface (Richards, 1931).

The value of the hydraulic head as defined by Bernoulli for a slowly flowing fluid is given by

$$
h_{\mathrm{w}}=\frac{p_{\mathrm{w}}}{\gamma_{\mathrm{w}}}+y
$$

with $p_{\mathrm{w}}$ the water pressure, $\gamma_{\mathrm{w}}$ the water specific mass and $y$ the gravity height.

The Darcy law is also assumed to be valid for a nonsaturated medium. Assuming an isotropic permeability, the velocity flow given by the generalised Darcy law can be written

$$
\underline{v}_{\mathrm{w}}=-K_{\mathrm{w}}\left(p_{\mathrm{c}}\right) \underline{\nabla} h_{\mathrm{w}}
$$

where the permeability scalar $K_{\mathrm{w}}$ depends on the suction pressure $p_{\mathrm{c}}$ (or on the saturation degree $S_{\mathrm{w}}$, as will be seen later) and $\underline{\nabla}$ is the gradient operator tensor.

Using the continuity equation and the generalised Darcy law, the Richards equation is obtained (Richards, 1931), which governs the flows in an undeformable non-saturated porous soil

$$
\frac{\partial \theta_{\mathrm{w}}}{\partial t}=\underline{\nabla}^{T}\left(K_{\mathrm{w}}\left(p_{\mathrm{c}}\right) \underline{\nabla} h_{\mathrm{w}}\right)
$$

where $\theta_{\mathrm{w}}=n S_{\text {ew }}$ is the water content, $S_{\text {ew }}$ is the current saturation ratio and $n$ is the porosity.

To summarise, this equation illustrates, under certain assumptions, that the flow in a non-saturated medium depends essentially on two hydrodynamic characteristics: water retention and permeability.

\section{Water retention curve}

The water retention curve must be studied in order to determine the hydraulic conductivity in a non-saturated soil. Many models propose an approximation of this curve (Brooks \& Corey, 1964; Campbell, 1974; Van Genuchten, 1980). In this study, the Van Genuchten relation has been chosen (Van Genuchten, 1980), which is probably the most commonly used, because it is simple and its expression can be differentiated to compute the hydraulic conductivity.

$$
S_{\mathrm{ew}}=S_{\mathrm{w}}+\frac{S_{\mathrm{w}}-S_{\mathrm{rw}}}{\left(1+\left(\alpha p_{\mathrm{c}}\right)^{\beta}\right)^{1-(1 / \beta)}}
$$

where, $S_{\mathrm{ew}}, S_{\mathrm{w}}$ and $S_{\mathrm{rw}}$ are, respectively, the effective, the maximal and the residual saturation degrees, $p_{\mathrm{c}}=p_{\mathrm{a}}-p_{\mathrm{w}}$ is the suction, $\alpha$ is a parameter related to the pore size distribution and $\beta$ is a parameter linked to the granulometry.

Water retention curve for the Trevoux event. The water retention curve used in the sand simulation corresponds to the results obtained by Liakopoulos (Liakopoulos, 1965) for Del Monte sand. For marls, account was taken of a curve corresponding to the interpolation of sand and classical clay results.

The soil-water characteristic curves of the materials are shown in Fig. 10 (parameters are given in Table 3).

Water retention curve for the Petacciato event. As there are no results on the relationship between the degree of saturation and suction for the Petacciato soil, a typical clay soil-water characteristic curve, presented in Fig. 11 (the parameters are given in Table 4), was considered for modelling.

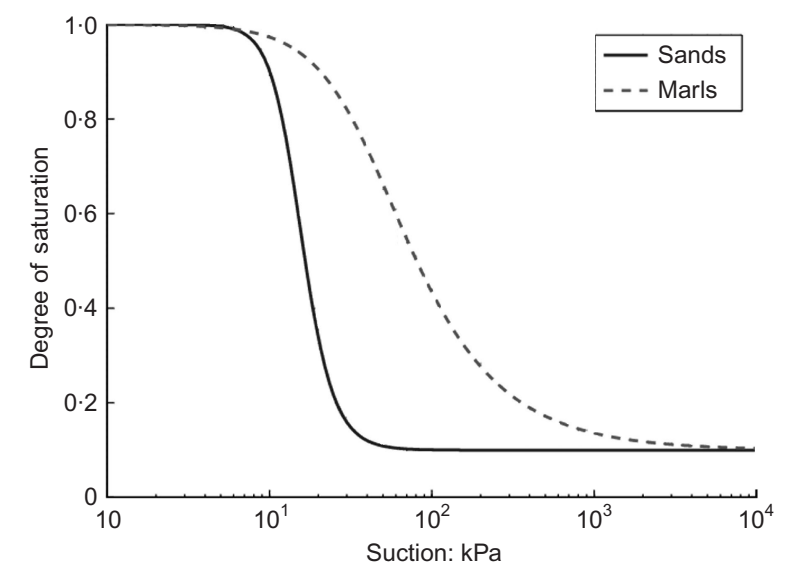

Fig. 10. Typical soil-water characteristic curves of sands and clays considered for the Trevoux soil 
Table 3. Parameters of the Van Genuchten model for Trevoux soil

\begin{tabular}{l|c|c|c|c}
\hline Parameters & Symbols & Unit & Sands & Marls \\
\hline Maximal degree of saturation & $S_{\mathrm{w}}$ & - & $1 \cdot 0$ & $1 \cdot 0$ \\
Residual degree of saturation & $S_{\mathrm{rw}}$ & - & $0 \cdot 1$ & $0 \cdot 1$ \\
First retention parameter & $\alpha$ & $\mathrm{Pa}^{-1}$ & $6 \cdot 8 \times 10^{-5}$ & $2.5 \times 10^{-5}$ \\
Second retention parameter & $\beta$ & - & $4 \cdot 8$ & $2 \cdot 0$ \\
\hline
\end{tabular}

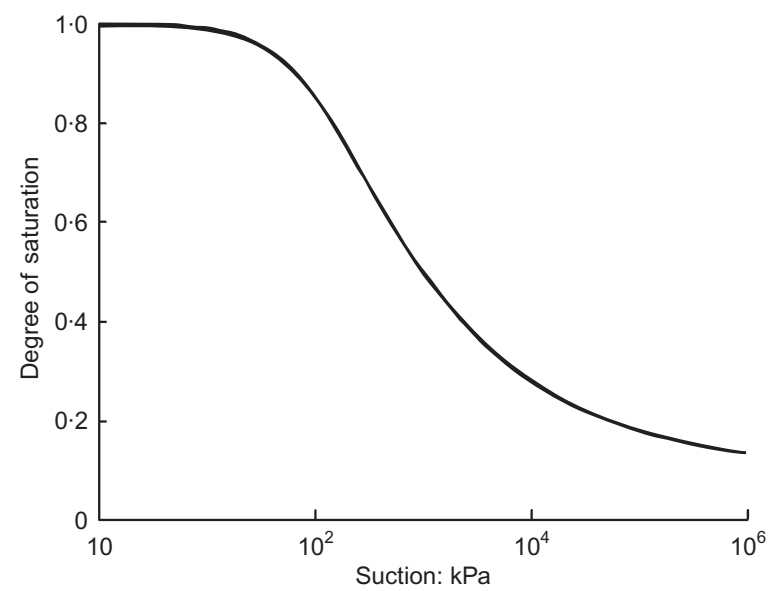

Fig. 11. Typical soil-water characteristic curve of clay considered for the Petacciato soil

\section{Permeability}

To analyse a transient flow problem in a saturated soil, the permeability coefficient is often assumed to be constant as a first approximation. However, for a deformable saturated or non-saturated soil, it may depend to a large extent on the void ratio and the saturation ratio. Several models have been proposed to characterise this variation (Mualem, 1986). Here, the linear variation of the permeability with the degree of saturation is considered

$$
K_{\mathrm{w}}=S_{\text {ew }} k_{\mathrm{w}}
$$

where $k_{\mathrm{w}}$ is the intrinsic permeability (corresponding to the fully saturated case).

\section{Effective stresses}

For saturated soils, the classical Terzaghi postulate gives the relation

$$
\underline{\sigma}^{\prime}=\underline{\sigma}-p_{\mathrm{w}} \underline{1}
$$

where $\underline{\sigma}^{\prime}$ is the Cauchy effective stress tensor, $\underline{\sigma}$ is the Cauchy total stress tensor and $p_{\mathrm{w}}$ is the pore water pressure.

A great deal of research (Croney et al., 1958) has been conducted to generalise the Terzaghi postulate, converging on the following relation (Bishop, 1959)

$$
\underline{\sigma}^{\prime}=\underline{\sigma}-p_{\mathrm{a}} \underline{1}+\chi\left(p_{\mathrm{a}}-p_{\mathrm{w}}\right) \underline{1}
$$

The parameter $\chi$ introduced here varies between 0 and 1 . The value 0 corresponds to a dry soil, while 1 corresponds to a saturated soil. In practice, many authors use the simple relation $\chi=S_{\text {ew }}$. This hypothesis was also used in the current authors' analysis.

\section{HILL'S SUFFICIENT CONDITION OF MATERIAL STABILITY}

In this paper, instead of using a plasticity criterion (limit equilibrium) and a localisation criterion, an instability criterion based on Hill's criterion is used. It consists in studying the sign of the second-order work at local and global scale.

\section{Second-order work criterion at a material point level}

Within the framework of continuum mechanics, Hill's sufficient stability criterion (Hill, 1958) states that a stressstrain state is stable if, for any values of $(\mathrm{d} \underline{\sigma}, \mathrm{d} \underline{\varepsilon})\left(\mathrm{d} \underline{\sigma}^{\prime}\right.$ for a non-dry soil) linked by the rate-dependent constitutive relation (stiffness matrix: M), the second-order work $d^{2} W$ defined below is strictly positive

$$
\begin{aligned}
& \forall(\mathrm{d} \underline{\sigma}, \mathrm{d} \underline{\varepsilon}) \in R^{2 n} \backslash\{0\} \text { with } \\
& \mathrm{d} \underline{\varepsilon}=\mathbf{M} \cdot \mathrm{d} \underline{\sigma}, d^{2} W=\mathrm{d} \underline{\sigma} \cdot \mathrm{d} \underline{\varepsilon}>0
\end{aligned}
$$

where $n$ is the stress space dimension. This criterion is then based on the fact that the operator must remain positive definite.

This can be illustrated with an undrained triaxial test on loose sand. The typical triaxial behaviour of loose sands is represented in Fig. 12, where $q$ passes through a maximum value which is strictly inside the Mohr-Coulomb plastic limit surface (Darve et al. 2004). Experiments show that if a small additional axial force is applied at the peak value of $q$, a sudden failure of the entire sample occurs with no localisation pattern (Khoa et al., 2006). Indeed, for axisymmetric undrained (isochoric) conditions, the second-order work is equal to $d^{2} W=\mathrm{d} q \cdot \mathrm{d} \varepsilon_{1} \quad\left(\varepsilon_{1}\right.$ : axial strain), which vanishes at $q$ peak (see Fig. 12)

This condition can be undertaken as follows: when the $d^{2} W$ sign changes continuously from a positive to a negative value along a given loading path, the material system passes from a state where deformation can be pursued only with an input of energy from an external agency, to a state where deformation can be pursued without any input of energy, at least in one loading direction. Indeed, in some configurations, failure requires energy input from an external agency (for example, shocks or impacts), while in other configurations it is not needed, so a perturbation with negligible

Table 4. Parameters of the Van Genuchten model considered for the Petacciato soil

\begin{tabular}{l|c|c|c}
\hline Parameters & Symbols & Unit & Clay \\
\hline Maximal degree of saturation & $S_{\mathrm{w}}$ & - & $1 \cdot 0$ \\
Residual degree of saturation & $S_{\mathrm{rw}}$ & - & $0 \cdot 1$ \\
First retention parameter & $\alpha$ & $\mathrm{Pa}^{-1}$ & $1 \cdot 0 \times 10^{-5}$ \\
Second retention parameter & $\beta$ & - & $1 \cdot 35$ \\
\hline
\end{tabular}




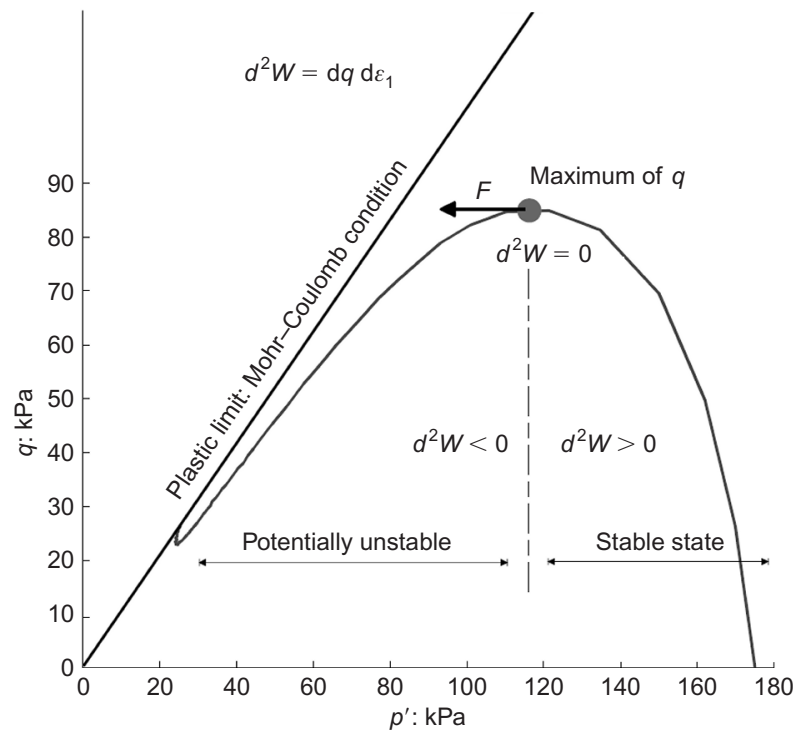

Fig. 12. Example of an unstable state related to a diffuse mode of failure strictly inside the Mohr-Coulomb plastic limit condition: typical undrained triaxial behaviour of a loose sand

energy can lead to failure (landslides, rockfall, etc.). This results in a burst of kinetic energy (Nicot \& Darve, 2007) and an exponential variation of the strains. This phenomenon has been numerically simulated using the discrete element method (Sibille et al., 2007).

Moreover, if the quadratic form of the second-order work is considered

$$
\begin{aligned}
d^{2} W & =\mathrm{d} \underline{\sigma} \cdot \mathrm{d} \underline{\varepsilon}=0 \Leftrightarrow \mathrm{d} \underline{\sigma} \cdot \mathbf{M} \cdot \mathrm{d} \underline{\sigma}=0 \\
& \Leftrightarrow \mathrm{d} \underline{\sigma} \cdot \mathbf{M}_{\mathrm{S}} \cdot \mathrm{d} \underline{\sigma}=0 \Leftrightarrow \operatorname{det}\left(\mathbf{M}_{\mathrm{S}}\right)=0
\end{aligned}
$$

where $\mathbf{M}_{\mathrm{S}}$ is the symmetric part of the stiffness matrix $\mathbf{M}$. As a consequence, the vanishing of the second-order work numerically corresponds with the first vanishing of one eigen value of the symmetric part of the stiffness matrix.

Considering the definition of $d^{2} W$ given in equation (15), it should be noted that the second-order work is a directional quantity in the stress space. Darve \& Laouafa (2000) have defined a procedure to determine the instability domain. It consists (for example in two dimensions (2D)) of two principal steps illustrated in Fig. 13

(a) for a given confining pressure, a triaxial compression or a triaxial extension is simulated by the constitutive relation

(b) along each triaxial path, we check by stress-probing in all directions for the first stress state that exhibits one stress direction giving a nil second-order work. This gives one point in the stress space of the boundary of the instability domain and a corresponding unstable direction. The procedure for different confining pressures to obtain the boundary of the instability domain is then pursued.

If the procedure is conducted for a stress state inside the instability domain, a set of unstable directions is found that can be grouped in a cone (Darve et al., 2004), as can be seen in the next example.

Figure 14 depicts the different cones of unstable directions and the potentially unstable domain for plane strain conditions corresponding to the Petacciato clay. A large domain of material instabilities in Hill's sense and bifurcations in the stress space strictly inside Mohr-Coulomb's criterion can be observed. This result is related to the fact that the positivity

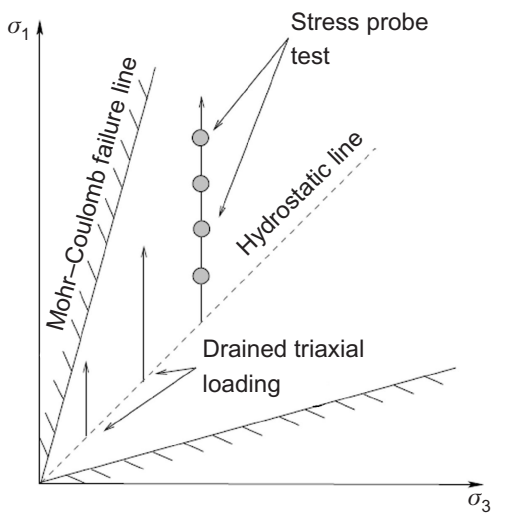

Stress probe test: incremental stress loading in all directions

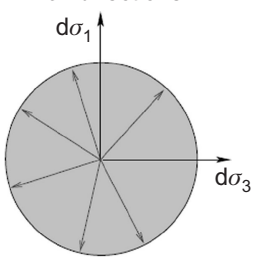

Fig. 13. Plane stress paths and stress rate probe test

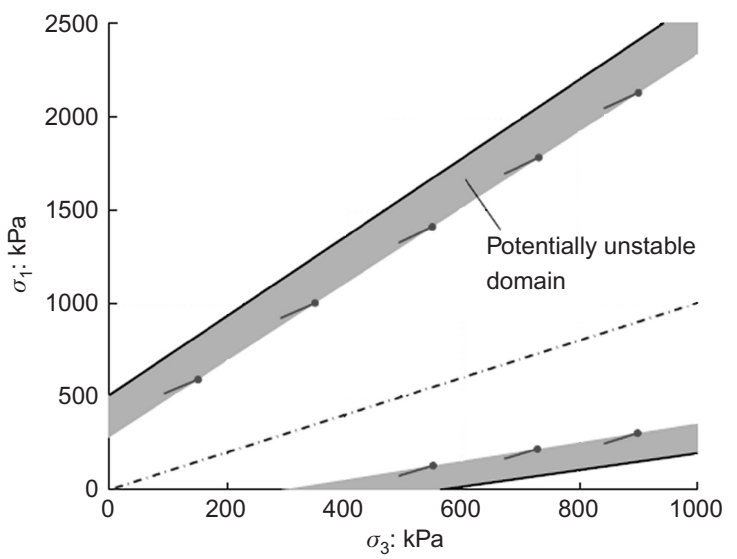

(a)

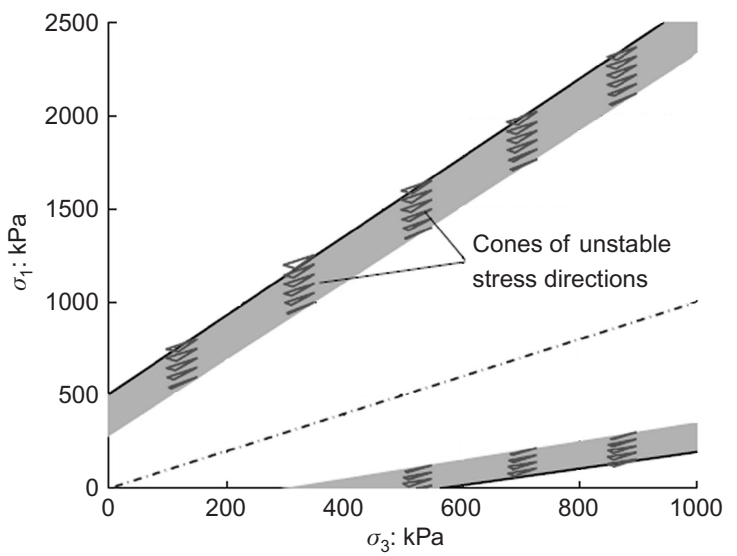

(b)

Fig. 14. (a) Potentially unstable domains and (b) cones of unstable directions for plane strain conditions in the case of blue-grey clay for the PLASOL model

criterion of a non-symmetric matrix $\mathbf{M}$ is always reached before the failure criterion corresponding to $\operatorname{det}(\mathbf{M})=0$. It is then directly linked to the non-symmetricity of the operator and thus the non-associated character of the plastic strains. 
More details about this instability criterion and its use can be found in literature (Darve et al., 2004; Laouafa \& Darve, 2002; Nicot \& Darve, 2006; Khoa et al., 2006).

In finite element computations, the second-order work is checked at all integration points pi (Gauss points) of the discretised domain between two successive and sufficiently close equilibrium steps of the incremental process

$$
d^{2} W_{p i}=\mathrm{d} \underline{\sigma}_{p i} \cdot \mathrm{d} \underline{\varepsilon}_{p i}
$$

In order to increase the readability of the $d^{2} W$ graphs, $d^{2} W$ is normalised in relation to the norm of the stress increment $\|\mathrm{d} \underline{\sigma}\|$ and the strain increment $\|\mathrm{d} \underline{\varepsilon}\|$ as follows

$$
d^{2} W_{p i}^{\mathrm{norm}}=\frac{d^{2} W_{p i}}{\left\|\mathrm{~d} \underline{\sigma}_{p i}\right\|\left\|\mathrm{d} \underline{\varepsilon}_{p i}\right\|}
$$

In the appropriate dual spaces, this quantity corresponds to the cosinus of the angle between vectors $\mathrm{d} \underline{\sigma}_{p i}$ and $\mathrm{d} \underline{\varepsilon}_{p i}$ and then belongs between -1 and 1 .

The spatial domain of negative values of $d^{2} W_{p i}^{\text {norm }}$ determines the potentially unstable area in the slope.

\section{Global second-order work criterion}

Hill (Hill, 1958) proposed a stability sufficient criterion for boundary problems where the geometry, the equilibrium equations, the initial conditions and the boundary conditions are taken into account. Hill's criterion for a domain $\Omega$ is reviewed below

$$
\begin{gathered}
\forall(\underline{\mathrm{d}} \underline{\sigma}, \mathrm{d} \underline{\varepsilon}) \in R^{2 n} \backslash\{0\} \text { with } \mathrm{d} \underline{\varepsilon}=\mathbf{M} . \mathrm{d} \underline{\sigma}, \\
D^{2} W=\int_{\Omega} \mathrm{d} \underline{\sigma} \cdot \mathrm{d} \underline{\varepsilon} \mathrm{d} \Omega>0
\end{gathered}
$$

In finite element analysis, the value of the global secondorder work $D^{2} W$ is the sum of the weighted values of $d^{2} W_{p i}$ for all integration points $\left(N_{p i}\right)$ of the medium

$$
\begin{aligned}
D^{2} W / & =\sum_{p i=1}^{N_{p i}} \mathrm{~d} \underline{\sigma}_{p i} \cdot \mathrm{d} \underline{\varepsilon}_{p i} \omega_{p i}\left|J_{p i}\right| \\
& =\sum_{p i=1}^{N_{p i}} D^{2} W_{p i}
\end{aligned}
$$

where $N_{p i}$ is the total number of integration points, $\left|J_{p i}\right|$ is the determinant of Jacobian matrix at integration point $p i$ and $\omega_{p i}$ is the integration weight factor for the same point.

To eliminate the influence of the mesh and of the loading increment size, a normalised form of the global second-order work $D^{2} W_{\text {norm }}$ is calculated in the following way

$$
D^{2} W_{\text {norm }}=\frac{1}{\sum_{p i=1}^{N_{p i}} \omega_{p i}\left|J_{p i}\right| \sum_{p i=1}^{N_{p i}}\left\|\underline{\mathrm{d}}_{p i}\right\|\left\|\mathrm{d}_{p i}\right\|}
$$

The vanishing value of $D^{2} W_{\text {norm }}$ along a given loading path determines the critical value of the loading parameter where the instability would become effective under a perturbation.

In the following, we will apply this stability criterion on two real landslide cases: the Trevoux landslide which occurred in France and the Petacciato landslide which occurred in Italy.

\section{NUMERICAL MODELLING OF THE TREVOUX LANDSLIDE}

Numerically modelling the landslide consists in a step-bystep rise of the water table: the first step corresponds to fully unsaturated soil; the next steps consist in an incremental rise until the flood level is reached. The computation is here broken down into 100 increments.

\section{Landslide analysis with a material stability criterion}

In this sub-section, Hill's criterion will be used to analyse the mechanisms of the Trevoux hillside landslide (see Fig. 15). In this figure, the real landslide surfaces that appeared and the conventional landslide surface obtained by classical failure criteria can both be seen.

The description of the area, where Hill's stability criterion is not fulfilled during the rising water level, is given in Figs 16-20. At step 30 (Fig. 16), the first negative values of the local second-order work appear at the foot of the hillside, which appears to be the most unstable zone. At this step, the water level has not yet reached the riverbed of the Saone River. Furthermore, a superficial zone of low $d^{2} W$ values is shown at the foot of the low fill layer and joins the foot of the retaining wall.

At step 50 of the rising water table (Fig. 17), the zone of negative $d^{2} W$ develops along the slope surface. The area of low $d^{2} W$ values clearly expands and reaches the top of the hillside.

When the Saone River approaches the foot of the Trevoux slope, the results plotted in Fig. 18 show that the unstable zone in Hill's sense moves towards two intermediate slopes. Moreover, the area of low $d^{2} W$ values considerably propagates to the top of the hillside while remaining superficial. While continuing to increase the water table up to the usual level of the Saône (Fig. 19), a concentration of negative $d^{2} W$ values is observed superficially at two intermediate slopes which connect the upper fill layer and the small retaining wall, and also between the two retaining walls themselves.

As soon as the Saône River reaches the flood level (the end of water rise; Fig. 20), a large zone of nil or negative $d^{2} W$ values is observed. This potentially unstable zone in Hill's sense coincides satisfactorily with the real landslide zones on the Trevoux hillside presented in Fig. 15. Thus the large superficial zone gathering the negative values of the secondorder work emphasises the real failure domain on this hillside.

These results confirm that the sufficient stability condition proposed by Hill (Hill, 1958), based on the sign of the second-order work, brings out the unstable material points as well as the potentially unstable zones in the Trevoux hillside.

\section{Global value of the second-order work}

Figure 21 shows the evolution of the normalised global second-order work $D^{2} W_{\text {norm }}$ defined by equation (20) plotted against the water level downstream. For the first steps (from 1 to 30 ) of the simulation, the rising water table from the impervious substratum does not yet produce significant

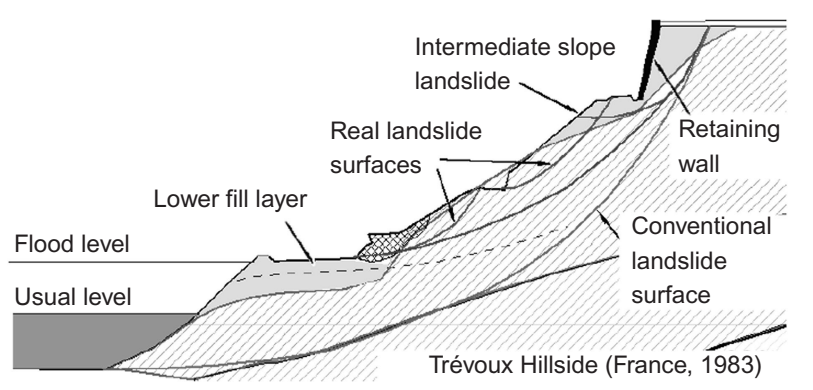

Fig. 15. Zoom of unstable zones 


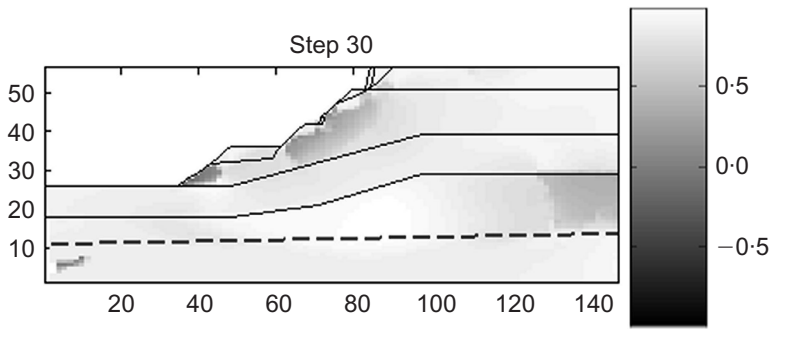

Fig. 16. Isovalues of the second-order work in the Trevoux slope at step 30 of the rising water table (dashed line)

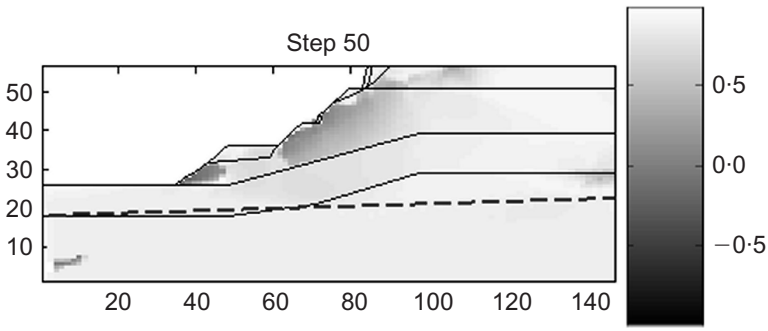

Fig. 17. Isovalues of the second-order work in the Trevoux slope at step 50 of the rising water table (dashed line)

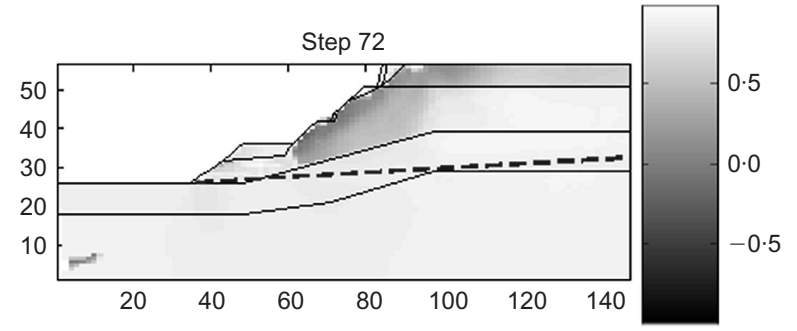

Fig. 18. Isovalues of the second-order work in the Trevoux slope at step 72 of the rising water table (dashed line)

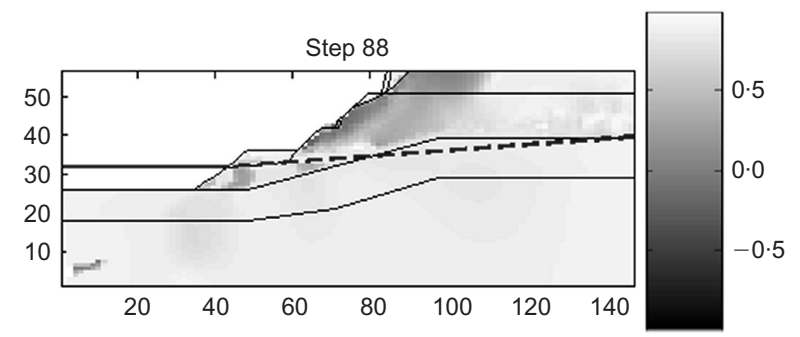

Fig. 19. Isovalues of the second-order work in the Trevoux slope at step 88 of the rising water table (dashed line)

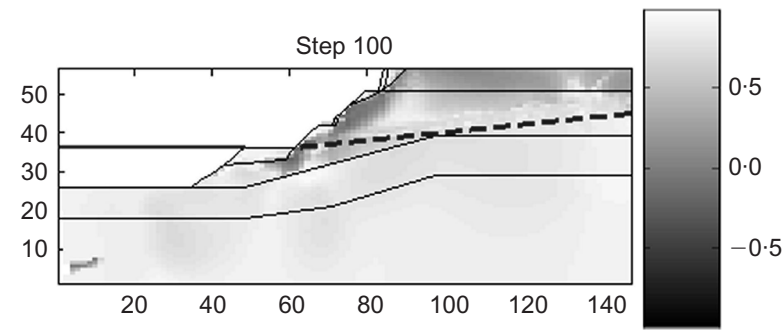

Fig. 20. Isovalues of the second-order work in the Trevoux slope at step 100 of the rising water table (dashed line)

mechanical effects on the slope. More precisely, at these loading steps, the increasing degree of saturation of the hillside causes decreasing suction and consequently the effective stress also decreases, but most stress states remain

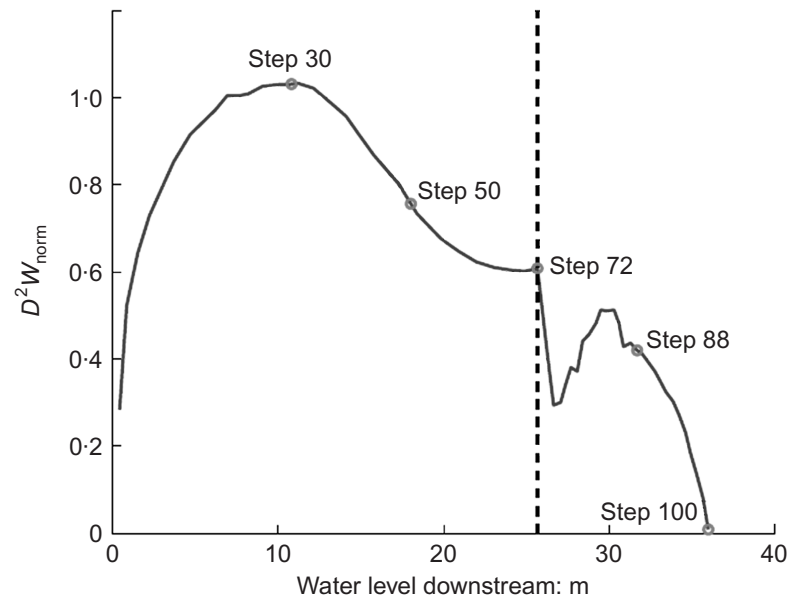

Fig. 21. Evolution of the global second-order work during the water table rise

far from the plastic limit criterion. So $D^{2} W_{\text {norm }}$ increases at the beginning (before step 30). On the other hand, when the water level approaches the Saône's riverbed, the Trevoux hillside tends towards a less stable state (a substantial displacement at the foot of the slope is noted in the computations), which is visible by expanding the low-value zone of $d^{2} W$ along the slope (Figs 16-20). This less stable state is probably described by the decreasing values of $D^{2} W_{\text {norm }}$ between steps 50 and 72 .

When the water starts to fill the Saône River (after step 72, the second phase in Fig. 17), the water level above the base of the river seems to have a stabilising influence for the hillside, perhaps because it is able to prevent an outflow until a certain water level is reached. Consequently, an increase in $D^{2} W_{\text {norm }}$ to $30 \mathrm{~m}$ of the downstream water level is observed. Furthermore, let us note that this water level corresponds to approximately $37.2 \mathrm{~m}$ of the upstream water level, which is close to the interface level $(39 \mathrm{~m}$ on the upstream side) between the gravelly sand layer (very permeable) and the gravelly marl layer (less permeable). We think that as long as the downstream water level is located lower than the boundary layer, the flow rate, depending on the material's hydraulic conductivity, is not yet high enough to destabilise the overall domain of the Trevoux hillside. Moreover, it is worth noting that even if the normalisation partly smooths the influence of the loading intensity, the size of the increment continues to influence Hill's global stability criterion and more precisely the magnitude of $D^{2} W$. On the other hand, this sign remains strictly independent of the normalisation procedure.

Increasing the water table level leads to a significant decrease in the normalised global second-order work. This global instability indicator for the Trevoux hillside during this saturation phase can be explained by the fact that the effective stress state decreases while simultaneously reaching the plastic limit criterion. When the flood level is reached, the reduction in the shear strength due to the reduction in suction as well as the outflow downstream are very unfavourable with respect to the stability of the Trevoux hillside. An almost nil value of $D^{2} W_{\text {norm }}$ at the end of simulation seems to be a good indicator to detect the effective loss of stability of a part of the hillside. At that state, the computations become divergent.

\section{NUMERICAL MODELLING OF THE PETACCIATO LANDSLIDE \\ Landslide analysis with a material stability criterion}

Hill's criterion is now used to analyse the Petacciato coastal slope stability with a rising water table. During the 
saturation process, the sign of the second-order work is computed at the end of each step for each integration point.

The description of the zones, where stability in Hill's sense is no longer fulfilled during the rising water level, is given in Figs 22-25. Let us recall that the area gathering the material points of nil or negative second-order work is potentially unstable. At step 25 of the rising water table (Fig. 22) it is observed that the $d^{2} W$ values are far from zero, so the coastal slope is always stable when the saturation reaches approximately $25 \%$ of the total height.

As the Petacciato slope continues to saturate up to $75 \%$, a few preliminary low $d^{2} W$ values from the foot of the coastal slope can be observed (see Fig. 23). When the water table approaches the free surface, the results of step 85, plotted in Fig. 24, show that the area of low $d^{2} W$ values develops considerably along the slope surface in a superficial manner.

As soon as $95 \%$ is saturated, there is a large zone of negative and low $d^{2} W$ (Fig. 25). It can clearly be seen that this potentially unstable zone coincides remarkably well with the real landslide zone on the Petacciato coastal slope. It is worth noting that the natural inclination of the slope is around $6^{\circ}$ and consequently the failure, which is in the diffuse mode, cannot be explained using either classical empirical methods or limit analyses.

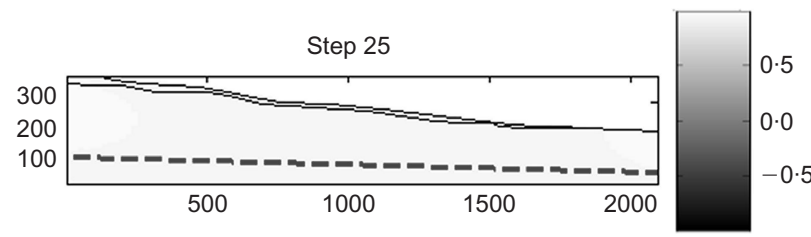

Fig. 22. Isovalues of the second-order work in the Petacciato slope at step 25 of the rising water table (given by the dashed line)

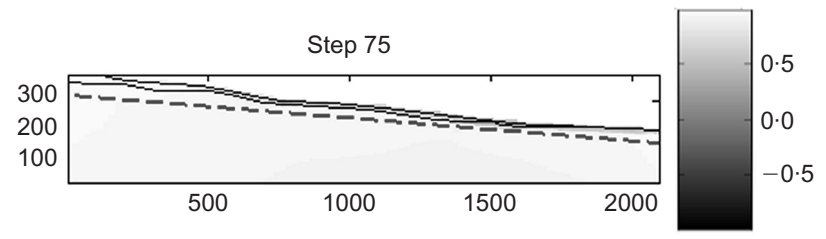

Fig. 23. Isovalues of the second-order work in the Petacciato slope at step 75 of the rising water table (given by the dashed line)

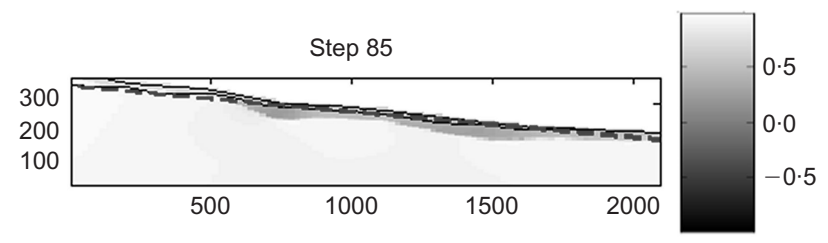

Fig. 24. Isovalues of the second-order work in the Petacciato slope at step 85 of the rising water table (given by the dashed line)

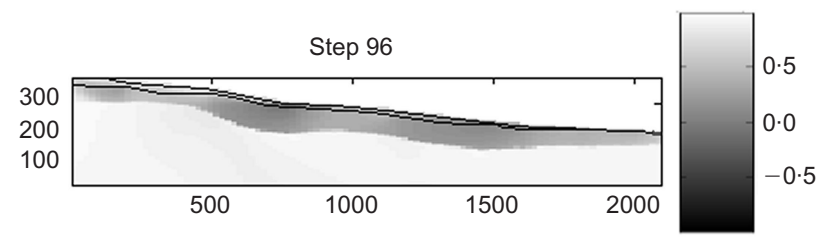

Fig. 25. Isovalues of the second-order work in the Petacciato slope at step 96 of the rising water table (given by the dashed line)
Global value of the second-order work

Figure 26 presents the evolution of the normalised global second-order work $D^{2} W_{\text {norm }}$ determined by equation (20) against the water level upstream. From the previous section, we know that the first steps of the rising water table from the impervious substratum produce no significant mechanical effects on the slope. As in the Trevoux case, at these steps, the saturation of the hillside causes a reduction in suction and consequently the effective stress also decreases, but most stress states remain far from the plastic limit criterion. Consequently, $D^{2} W_{\text {norm }}$ increases at the beginning. As the water table continues to rise, a considerable decrease is observed in the normalised global second-order work. This global instability of the Pettaciato coastal slope during this saturation phase results from the effective stress state decreasing while simultaneously approaching the plastic limit criterion. When $95 \%$ of this slope is saturated, the strong reduction in the shear strength owing to the suction reduction as well as the outflow in downstream is highly unfavourable. A very low value of $D^{2} W_{\text {norm }}$ at the end of the simulation seems to be a good indicator to forecast the loss of stability in the entire slope if perturbations are imposed (low seismic events, excavations, etc.). However, in this case, the loss of numeric convergence occurs too soon to obtain the nil value of the global second-order work.

\section{Comparison of the results with another model}

To corroborate the results obtained with Lagamine, the Petacciato landslide was simulated with another finite element code: Plaxis. This code is based on the hard soil model (HSM) constitutive relation, which is a hardening-softening non-associated elasto-plastic model. The corresponding parameters are presented in Table 5.

The loading is the same as previously: we consider a rise of the water table. Figs 27-31 present the local second-order work changes in the slope during the simulation. As with Lagamine, a zone of low $d^{2} W$ values develops along the slope's surface. The final result at step 97 is similar to the result obtained at step 96 with Lagamine.

The global second-order work changes are also similar, with very slight changes before step 75 , followed by a fast reduction until convergence is lost (steps 96-97), as illustrated in Fig. 32.

Comparing the results obtained with Lagamine and PLASOL illustrates the robustness of the stability criterion based on the sign of the second-order work.

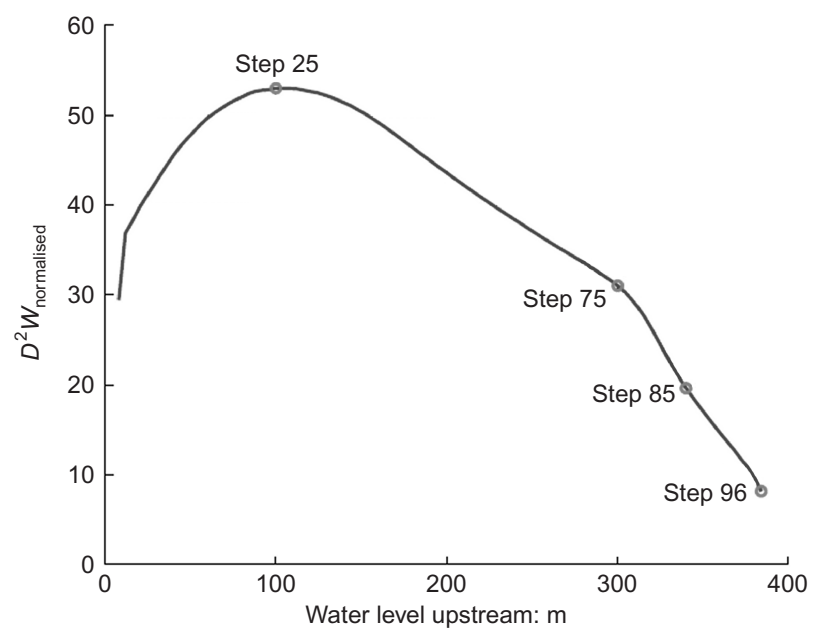

Fig. 26. Evolution of the global second-order work during the rising water table 
Table 5. Mechanical parameters of the HSM model for the Petacciato soils

\begin{tabular}{l|c|c|c}
\hline Soil parameters & Symbols & Unit & $\begin{array}{c}\text { Blue-grey } \\
\text { clay }\end{array}$ \\
\hline Grain specific weight & $\rho_{\mathrm{s}}$ & $\mathrm{kN} / \mathrm{m}^{3}$ & $27 \cdot 5$ \\
Secant modulus & $E_{50}^{\mathrm{ref}}$ & $\mathrm{MPa}$ & 60 \\
Tangent modulus & $E_{\mathrm{oed}}^{\mathrm{ref}}$ & $\mathrm{MPa}$ & 66 \\
Poisson's ratio & $v$ & - & $0 \cdot 18$ \\
Porosity & $n$ & - & $0 \cdot 3$ \\
Intrinsic permeability & $k_{\mathrm{w}}$ & $\mathrm{m}^{2}$ & $10^{-17}$ \\
Friction angle & $\varphi_{0}$ & $\mathrm{deg}$ & 18 \\
Cohesion & $c$ & $\mathrm{kN} / \mathrm{m}^{3}$ & 165 \\
Dilatancy angle & $\psi$ & $\mathrm{deg}$ & 0 \\
\hline
\end{tabular}

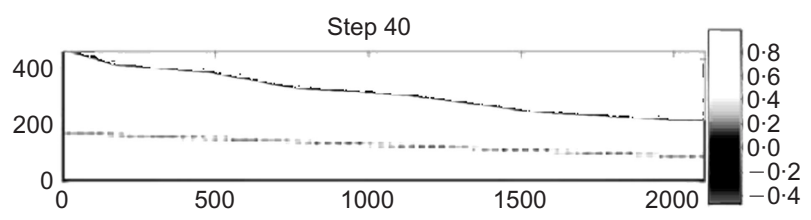

Fig. 27. Isovalues of the second-order in the Petacciato slope obtained with Plaxis at step 40

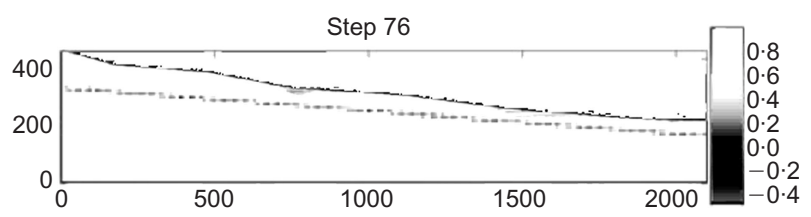

Fig. 28. Isovalues of the second-order in the Petacciato slope obtained with Plaxis at step 76

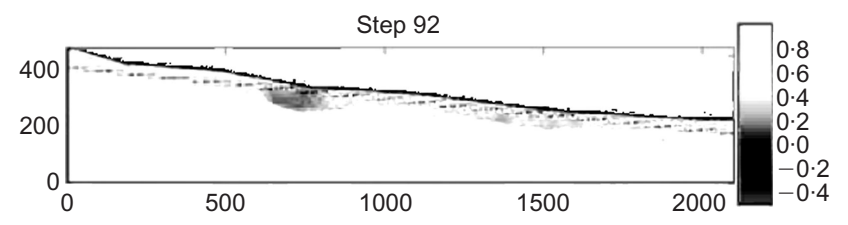

Fig. 29. Isovalues of the second-order in the Petacciato slope obtained with Plaxis at step 92

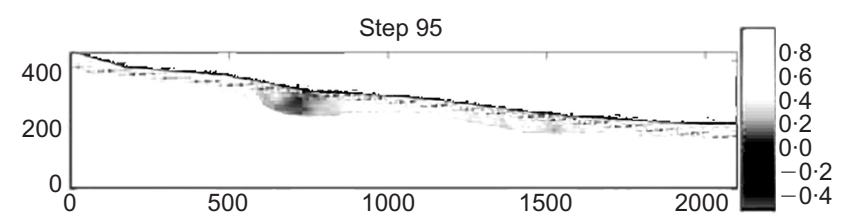

Fig. 30. Isovalues of the second-order in the Petacciato slope obtained with Plaxis at step 95

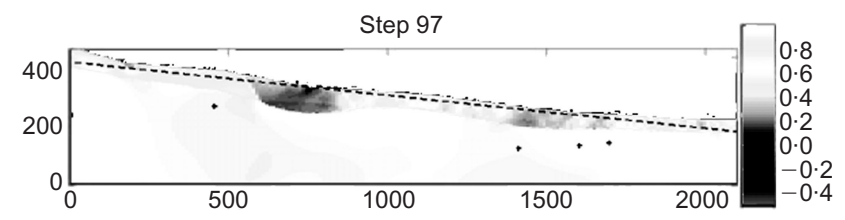

Fig. 31. Isovalues of the second-order in the Petacciato slope obtained with Plaxis at step 97
As shown by the elasto-plastic theory, the necessary ingredients to describe diffuse and localised failure modes are to take into account a hardening non-associated elastoplastic relation.

\section{CONCLUSION}

In this paper, Hill's sufficient stability condition was applied. Both local and global sufficient stability criteria (or necessary instability criteria) based on the sign of the second-order work, which can detect the instability states and directions at the material scale as well as for the entire domain, are proposed. The use of these stability criteria in finite element analysis is also described.

Then, by considering an elasto-plastic non-associated model and the second-order work criterion, it was shown that for cohesive frictional materials, unstable stress-strain states can be demonstrated for plane strain conditions, strictly inside the plastic limit criterion. The specific trends of this instability criterion can be summarised as follows

(a) this is the first bifurcation criterion reached, if flutter instabilities are excepted

(b) to differ from a plastic limit criterion, hardening nonassociated elasto-plastic relations must be considered

(c) the boundary of the bifurcation domain, inside the Mohr-Coulomb plastic limit surface, is approximately conical

(d) inside the bifurcation domain, there are cones of unstable stress directions

(e) the failure mode associated with this criterion is of the diffuse type.

Then two real cases of landslides that have occurred on the Trevoux hillside (France) and the Petacciato coastal slope (Italy) were analysed using this criterion. Finite element modelling, in which the unsaturated hydro-mechanical coupling is taken into account, was carried out. An original approach to stability analysis at both local and global levels using the second-order work criterion makes it possible successfully to delineate the main unstable zones on these slopes resulting from a long rainy period. In the two examples presented here, the global second-order work allows describing the effective stability of the domain but it is not convenient to localise the collapse zone, indicate the instant of global instability or answer questions concerning the triggering failure mechanism. On the other hand, it appears that the local stability criterion is an interesting indicator for describing the unstable areas and thus certain failure modes (localised, diffuse). The propagation of poten-

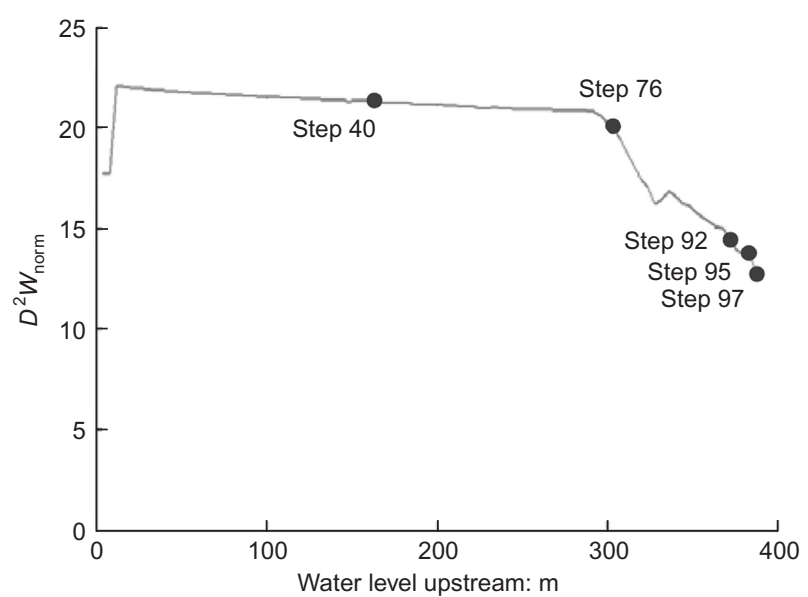

Fig. 32. Evolution of the global second-order work obtained with Plaxis 
tially unstable zones towards the free surface of the body is also an interesting feature to capture. Briefly, these two cases have verified that

(a) the potentially unstable area can be detected by the material points where the second-order work takes negative values

(b) the failure becomes effective under certain perturbations when the global second-order work is vanishing

(c) diffuse failure modes (detected by second-order work criterion) can explain landslides under very low slope angles.

\section{ACKNOWLEDGEMENTS}

The authors are very grateful for the support provided by the European projects LESSLOSS (6th PCRD) and DIGA (5th PCRD), and by the national French project SIGMA (ANR-PGCU).

\section{REFERENCES}

Aitchinson, G. D. (1961). Relationship of moisture stress and effective stress functions in unsaturated soils. Pore Pressure and Suction in Soils, pp. 47-52. London: Butterworth.

Barnichon, J. D. (1998). Finite element modelling in structural and petroleum geology. PhD thesis, University of Liège.

Bigoni, D. \& Hueckel, T. (1991). Uniqueness and localization-i: associative and non-associative elastoplasticity. Int. J. Solids Structs 28, No. 2, 197-213.

Bishop, A. W. (1959). The principle of effective stress. Teknisk Ukeblad 39, 859-863.

Bureau de Recherches Géologiques et Minières. (1983). Assistance technique à la mairie de Trevoux pour les phénomène à instabilité de versant affectant la commune, Technical report. Orléans: BRGM.

Brooks, R. H. \& Corey, A. T. (1964). Hydraulic properties of porous media. Hydrology paper, Colorado State University, Fort Collins.

Campbell, G. S. (1974). A simple method for determining unsaturated conductivity from moisture retention data. Soil Sci. 117, No. 6, 311-314.

Childs, E. C. \& Collis-George, N. (1950). The permeability of porous materials. Proc. Roy. Soc. Lond., Ser. A. 210, 392-405.

Croney, D., Coleman, J. D. \& Black, W. P. M. (1958). The movement and distribution of water in soil in relation to highway design and performance, Special report No 40. Washington: Highway Research Board.

Darve, F. (1996). Liquefaction phenomenon of granular materials and constitutive instability. Int. J. Engng Comput. 7, 5-28.

Darve, F. \& Chau, B. (1987). Constitutive instabilities in incrementally non-linear modelling. Constitutive Laws for Engineering Materials: Theory and Applications (eds C. S. Desai and G. H. Gallacher), 301-310.

Darve, F., Flavigny, E. \& Meghachou, M. (2000). Constitutive modelling and instabilities of soil behaviour. Comput. Geotech. 17, No. 2, 203-224.

Darve, F. \& Laouafa, F. (1994). Stability and uniqueness in geomaterials constitutive modelling. Localisation and Bifurcation Theory for Soils and Rocks (eds R. Chambon et al.), pp. 73-88. Rotterdam: A. A. Balkema.

Darve, F. \& Laouafa, F. (2000). Instabilities in granular materials and application to landslides. Mech. Cohesive-Frictional Mater. 5, No. 8, 627-652.

Darve, F., Servant, G., Laouafa, F. \& Khoa, H. D. V. (2004). Failure in geomaterials: continuous and discrete analyses. Comput. Methods in Appl. Mech. Engng 193, 3057-3085.

Darve, F. \& Vardoulakis, I. (2004). Degradations and instabilities in geomaterials (eds F. Darve and I. Vardoulakis). New York: Springer Verlag.

Duncan, J. M. (1996). State of the art: limit equilibrium and finite element analysis of slopes. J. Geotech. Engng, ASCE 122, No. 7, 577-596.

Espinoza, R. D., Repetto, P. C. \& Muhunthan, B. (1996). General framework for stability analysis of slopes. Géotechnique 42, No. 4, 603-615.

Fredlund, D. G. \& Xing, A. (1994). Equations for the soil-water characteristic curve. Can. Geotech. J. 31, 521-532.

Gaden, L. \& Desvarreux, P. (2001). Trevoux: Résultats de la reconnaissance géotechnique du 29 mai 2001. Technical report. SAGE: Société Alpinede Géotechnique.

Gaden, L. \& Desvarreux, P. (2002). Trevoux: Indentification des matériaux. résultats des essais de laboratoire. Technical report. Grenoble: Société Alpine de Géotechnique.

Griffiths, D. V. \& Lane, P. A. (1999). Slope stability analysis by finite elements. Géotechnique 49, No. 3, 387-403.

Hazen, A. (1911). Discussion of dams on soil foundations. Trans. Amer. Soc. Civil Engrs 73, 199.

Hill, R. (1958). A general theory of uniqueness and stability in elastic-plastic solids. J. Mech. Physics Solids 6, 239-249.

Jennings, J. E. B. (1961). A revised effective stress law for use in the prediction of the behaviour of unsaturated soils. Pore pressure and suction in soils, pp. 26-30. London: Butterworth.

Khoa, H. D. V., Georgopoulos, I.-O., Darve, F. \& Laouafa, F. (2006). Diffuse failure in geomaterials: experiments and modelling. Comput. Geotech. 33, 1-14.

Laouafa, F. \& Darve, F. (2002). Modelling of slope failure by a material instability mechanism. Comput. Geotech. 29, No. 4, $301-325$.

Liakopoulos, A. C. (1965). Retention and distribution of moisture in soils after infiltration has ceased. Bull. Int. Assoc. Sci. Hydrol. 10, No. 2, 58-69.

Mualem, Y. (1986). Hydraulic conductivity of unsaturated soil: prediction and formulas. In Methods of soil analysis, Number 9. Part 1 (ed. A. Klute), pp. 799-823. Madison: American Society of Agronomy.

Nicot, F. \& Darve, F. (2006). Micro-mechanical investigation of material instability in granular assemblies. Int. J. Solids Structs 43, 3569-3595.

Nicot, F. \& Darve, F. (2007). Micro-mechanical bases of some salient constitutive features of granular materials. Int. J. Solids Structs. 44, Nos 22-23, 7420-7443.

Nova, R. (1994). Controllability of the incremental response of soil specimens subjected to arbitrary loading programmes. J. Mech. Behavior of Mater. 5, No. 2, 193-201.

Nova, R. (2004). Controllability of geotechnical testing. Revue Française de génie civil 8, No. 5-6, 613-634.

Rice, J. R. (1976). The localization of plastic deformation. Theoretical and applied mechanics (ed. W. T. Koiter), vol. 8, pp. 207-220. Amsterdam: North-Holland publishing Company.

Richards, L. A. (1931). Capillary conduction of liquids through porous mediums. Physics 1, No. 5, 318-333.

Studio Geotecnico Italiano (2004). The Petacciato landslide (Campobasso-Italy): geological and geotechnical data, LESSLOSS report. Milan: SGI.

Shepherd, R. G. (1989). Correlations of permeability and grain size. Ground Water 27, 633-638.

Sibille, L., Nicot, F., Donze, F. \& Darve, F. (2007). Material instability in granular assemblies from fundamentally different models. Int. J. Numer. Analyt. Methods Geomech. 31, No. 3, 457-482.

Van Eekelen, H. A. M. (1980). Isotropic yield surfaces in three dimensions for use in soil mechanics. Int. J. Numer. Analyt. Methods Geomech. 4, 89-101.

Van Genuchten, M. T. (1980). A closed-form equation for predicting the hydraulic conductivity of unsaturated soils. Soil Sci. Soc. Amer. J. 44, 892-898.

Vardoulakis, I. (1976). Equilibrium theory of shear bands in plastic bodies. Mech. Res. Commun. 3, No. 3, 209-214.

Wyllie, M. R. J. \& Gardner, G. H. F. (1985). The generalized Kozeny-Carmen equation 11: a novel approach to problems of fluid flow. World Oil (Production Section) 146, 210-228.

Zienkiewicz, O. C. \& Taylor R. L. (1994). The finite element method. Basic formulations and linear problems. London: McGraw-Hill. 